\title{
El soporte multiplataforma como clave de éxito de la Narración Transmedia. Estudio de caso del webdoc "Las Sinsombrero"
}

\section{The cross-platform format as key of sucess in Transmedia Storytelling. Case of study: "Las Sinsombrero" webdoc}

\author{
María Isabel Rodríguez Fidalgo \\ Profesor Contratado Doctor Departamento de Sociología y Comunicación \\ (Universidad de Salamanca) \\ Adriana Paíno Ambrosio \\ Doctoranda Departamento de Sociología y Comunicación \\ (Universidad de Salamanca) \\ Lucía Jiménez Iglesias \\ Doctoranda Departamento de Biblioteconomía, Documentación \\ y Comunicación Audiovisual \\ (Universitat de Barcelona)
}

Fecha de recepción: 8 de mayo de 2016

Fecha de revisión: 22 de junio de 2016

Para citar este artículo: Rodríguez Fidalgo, M. I., Paíno Ambrosio, A. y

Jiménez Iglesias, L. (2016): El soporte multiplataforma como clave de éxito de la Narración Transmedia. Estudio de caso del webdoc "Las Sinsombrero", Icono 14, volumen 14 (2), pp. 304-328. doi: 10.7195/ri14.v14i2.967 


\section{Resumen}

Internet ha revolucionado el consumo mediático y a raíz de las potencialidades que ofrece dicho soporte nuevas narrativas interactivas han visto la luz. Es el caso de las denominadas narrativas crossmedia y transmedia. Partiendo de este contexto, se plantea el estudio de caso del proyecto "Las Sinsombrero". El objetivo planteado es analizar bajo una perspectiva metodológica cualitativa su estructura narrativa multiplataforma y poder con ello determinar la función innovadora que cumplen cada una de las plataformas a través de las cuales se expande la historia. La citada investigación constata la convivencia, dentro del mismo proyecto, de dos tipos de narrativas multiplataforma: crossmedia y transmedia. En este caso es la variable de interacciónparticipación-contribución de los usuarios la principal diferencia y lo que permite establecer las innovaciones narrativas más significativas entre ambos tipos de narraciones multiplataforma.

Palabras clave: Narrativas transmedia - Narrativas crossmedia - Webdoc - Documental - Documental interactivo - Prosumidor - Contenido generado por el usuario (CGU)

\section{Abstract}

Internet has revolutionized media consumption and due to the possibilities this new medium offers new interactive narrative models have emerged, such as crossmedia and transmedia storytelling. In this scenario, a case study about "Las Sinsombrero" project is considered in this paper. The objective is to analyse its narrative multiplatform structure in order to establish the innovative functions accomplished by each of the formats used to spread the story. Such a research confirms the coexistence of two multiplatform narrative models (crossmedia and transmedia) in the project. In this case, there is also a variable which represents the key differences between both multiplatform models and which implies the most significant narrative innovations that distinguishes them: the interaction-involvement-contribution of users.

Key Words: : Transmedia storytelling - Crossmedia storytelling - Web documentary Documentary - Interactive documentary - Prosumer - User-generated content (UGC) 
El soporte multiplataforma como clave de éxito de la Narración Transmedia... 306

MONOGRÁFICO

\section{Introducción}

La transformación del mundo analógico en digital ha revolucionado los medios de comunicación generando nuevos soportes y cambiando los modelos comunicacionales tradicionales (Moreno, 2001). Con Internet los mecanismos de producción de información, almacenamiento, difusión, acceso y consumo, se han visto modificados dando lugar a nuevas dinámicas entre productores, realizadores, distribuidores y consumidores (Area \& Pessoa, 2012; Rodríguez \& Molpeceres, 2013) configurándose con ello un nuevo panorama mediático. Este nuevo escenario que ha emergido con la aparición de la Word Wide Web ha supuesto una oportunidad para los profesionales de la información que tratan de aprovechar todo el potencial que ofrece el nuevo medio (Orihuela, 2002). En este contexto, el periodista tiene que ser capaz de elaborar productos informativos novedosos, pero también de relacionarse con sus consumidores gracias al poder de las nuevas tecnologías. El cambio que ha experimentado el periodismo es tan profundo que lo único que ha permanecido intacto es su propia esencia y la necesidad de poner en manos del público la información necesaria para poder moverse en la sociedad (Díaz-Campo, 2014; López, 2011). “Entramos en una era de transición y transformación prolongada en el modo de operar de los medios" (Jenkins, 2008:33). Internet, por tanto, redefine el perfil de los profesionales de la comunicación, pero también de los propios medios que tienen que adaptarse, por una parte, al nuevo soporte, y por otra, al público receptor que demanda otro tipo de contenidos. Los consumidores de contenidos digitales están adquiriendo a su vez nuevas dimensiones. El rol pasivo que venían desempeñando tradicionalmente las audiencias ha dado paso a un usuario participativo en el proceso comunicativo en la medida en que selecciona los contenidos que quiere consumir en cada momento llegando incluso a convertirse, en algunos casos, en coautor de los mismos (Rodríguez \& Molpeceres, 2013). Estaríamos pues ante lo que Isidro Moreno calificó como "lectoautores", es decir, lectores que participan en el proceso narrativo (Caldevilla, 2009; Moreno 2001), o lo que muchos años atrás, ya por los años 80, Alvin Toffler denominó "prosumidores", término que utilizó para referirse a esa unión entre productor y consumidor (Toffler, 1980). El receptor pasivo de los medios tradicionales ha dado paso a un usuario activo que quiere interactuar con la información. Se ha producido un cambio de actitud de los consumidores que ya no dudan en ir más allá de ese rol para convertirse 
en productores de nuevos contenidos (Scolari, 2013). En este sentido será fundamental la aparición de nuevos formatos innovadores a la hora de contar historias y de presentar el contenido y que no podrán olvidar la importancia que adquiere dentro de los mismos la participación de los usuarios. Este es el caso de los nuevos documentales interactivos, dentro del contexto de los contenidos de no ficción, los cuales aprovechando las grandes potencialidades que posibilitan ahora los sistemas multiplataformas, ofrecen información sobre la realidad a los usuarios a través de un nuevo relato hipertextual, pero a diferencia de los clásicos documentales este nuevo formato permite acercarse si cabe aún más a esa realidad narrada, puesto que pueden contemplar dentro de dicha narrativa del relato multiplataforma e hipertextual la posibilidad de contribuir a ampliar la narración por parte de los usuarios. Estas características del nuevo documental ubicado ahora en el soporte digital abre sin duda, nuevas líneas de análisis de análisis dentro del género.

\section{Aportes teóricos}

Internet ha roto la verticalidad del flujo informativo dando lugar a un fenómeno de feedback real entre los integrantes del mensaje informativo (productor de información y consumidores) en la que los roles se entremezclan (Meso, 2006). El público quiere participar e interactuar y ya no se conforma con recibir la información y el entretenimiento de forma aislada. Es en este momento cuando surge el concepto de narrativa transmedia (en adelante NT) acuñado por Henry Jenkins (2003). La NT hace referencia a la expansión de un relato a través de diferentes medios 0 soportes (videojuegos, cómics, novelas, películas, webseries, etc.) de modo que cada uno de estos medios realiza una aportación al desarrollo de la historia, pero siempre tratando de crear una experiencia de entretenimiento unificada y coordinada. No se trata de una adaptación o una transposición sino que en la narración transmediática cada medio ofrece algo nuevo al relato que enriquece el conjunto de la narración (Jenkins, 2003; 2007; 2008; 2009; 2010; 2014).

Ahora bien, existe una gran diversidad de términos que se refieren a estas nuevas narrativas audiovisuales en las que intervienen diferentes medios y que han surgido a raíz de la convergencia mediática, entre los se pueden señalar dos: crossmedia y multiplataforma (Costa \& Piñeiro, 2012). Esta variedad de conceptos 
hace necesario establecer brevemente una diferenciación entre éstos y las narrativas transmedia. El relato multiplataforma consiste en la adaptación de una única historia en diferentes medios o soportes, adaptándose al lenguaje y la forma propios de cada uno de ellos (Costa \& Piñeiro, 2012); es decir, se ofrece a los usuarios el mismo contenido en más de un medio. Dentro de esta modalidad narrativa se enmarcan por ejemplo todos los productos relacionados con la historia de Harry Potter. La narración crossmedia, por su parte, no se limita a la adaptación del relato a diferentes soportes sino que, en este caso, cada uno de esos medios va a aportar algo nuevo a la historia, de modo que el usuario debe seguir el producto a través de los diferentes canales (Paíno \& Rodríguez, 2015). Cada una de las partes que conforman la narración crossmedia no pueden ser consumidas de forma autónoma puesto que los fragmentos por separado no tienen sentido si la audiencia no experimenta la totalidad de la experiencia. Esta es la principal diferencia con la narración transmedia donde no solo aparecen diferentes contenidos desarrollados en diversas plataformas que forman parte del mismo universo narrativo sino que estas partes, además, son independientes entre ellas y tienen sentido completo en sí mismo, de modo que pueden ser consumidas de forma autónoma (Paíno \& Rodríguez, 2015; Costa \& Piñeiro, 2012).

A esta idea de despliegue del relato se suma otra característica fundamental de las NT, y es que los consumidores adoptan un rol activo en dicha expansión; "no basta con que la participación de la audiencia sea activa sino que ha de establecer un diálogo creativo con el relato base, llegando a modificarlo en el proceso" (Rodríguez \& Molpeceres, 2014:318). El usuario de las NT es un prosumidor que participa en el proceso creativo. "Ya sea escribiendo una ficción y colgándola en Fanfiction, o grabando una parodia y subiéndola a YouTube, los prosumidores del siglo XXI son activos militantes de las narrativas que les apasionan" (Scolari, 2013:27). Se puede señalar aquí otro concepto que es el "Contenido Generado por el Usuario" (CGU), que hace referencia a aquellas manifestaciones que realizan los fans en torno a una producción (Scolari, Jiménez y Guerrero, 2012). Estos contenidos generados por los usarios-espectadores pueden ser de muchos tipos y van a pasar a denominarse de diferentes formas en función del formato que utilicen, ya sea texto (fanfiction), vídeo (fanvids), dibujos (fanarts), comunidades (fandoms), etc. (Paíno \& Rodríguez, 2015). 


\subsection{Del formato clásico del documental al webdoc}

Desde el tradicional documental clásico iniciado por los hermanos Lumière (Liuzzi, 2014; Rodríguez \& Molpeceres, 2014; Sellés, 2008) y continuado por Robert Flaherty en 1922 con la primera película documental, Nanook of the North (Gifreu, 2010; Liuzzi, 2014), el género documental no ha dejado de ser la principal herramienta para trasladar historias de no ficción sobre aspectos de la vida real; y actualmente, en palabras de Gifreu, "sigue aportando al público experiencias únicas, representado la vida real y proporcionando observaciones y reflexiones de fondo sobre la cultura, la política, las ideologías y las personas" (2010: 91).

El documental ha experimentado notables transformaciones en su historia derivados de los cambios sociales, culturales, políticos y tecnológicos, pero también en gran medida de las exigencias de un público cada vez más preparado. En especial en las últimas dos décadas

(...) la producción de documentales tradicionales se ha visto complementada y enriquecida por un conjunto de aplicaciones multimedia, las cuales han afectado a las lógicas de producción, exhibición y recepción audiovisual del género documental. (Gifreu, 2013: 28)

Remitiéndose a la teoría propuesta desde la "Ecología de los Medios" (Marshall McLuhan (1964), Neil Postman (1992), Scolari (2010) entre otros) que alude a la idea de que fruto de la evolución tecnológica los medios de comunicación han de concebirse como especies que conviven dentro de un ecosistema en el cual nacen, se transforman y luchan por adaptarse y sobrevivir, se puede decir que dichos aspectos pueden trasladarse en este caso también al género documental. Éste lejos de mirar para otro lado a las potencialidades que ofrecen los avances técnicos ha conseguido adaptarse a los cambios derivados del actual panorama comunicacional haciéndose un hueco en el escenario digital en el que las características del propio documental, en cuanto a la representación de la realidad, se han unido a las posibilidades de navegación e interacción del medio digital (Gifreu, 2010: 10). Pero aunque las características del soporte Internet (multimedialidad, hipertextualidad e interactividad) han propiciado la aparición de un nuevo tipo de documental 
El soporte multiplataforma como clave de éxito de la Narración Transmedia... 310

(Rodríguez \& Sánchez, 2014), hay algo que no ha variado y que continúa en la actualidad, que es la intención de contar historias relacionadas con acontecimientos reales (Rodríguez \& Molpeceres, 2013). Como señala Nichols:

Los documentales son una ficción con tramas, personajes, situaciones y sucesos como cualquier otra. Ofrecen carencias, retos o dilemas en la introducción; van construyendo tensiones cada vez mayores y conflictos de creciente dramatismo, y acaban con una resolución y la clausura. Hacen todo esto con referencia a una «realidad» que es una construcción, el producto de sistemas significantes, como el propio documental. (Nichols, 1997: 149)

La esencia del documental, la captación de la realidad, permanecerá intacta independientemente del soporte utilizado para difundir el documental, aunque cada medio ofrecerá unas características determinadas desde el punto de vista de la construcción narrativa (Rodríguez \& Sánchez, 2014). Este es el punto más importante que comparten el documental lineal y el interactivo, y es que tanto uno como otro pretenden documentar la realidad, aunque "el tipo de material en referencia a los medios y preferencias de sus autores y participantes acaban creando un producto final muy diferente" (Gifreu, 2013: 114).

Los documentales clásicos mezclan la realidad con la experiencia del propio documentalista.

El documentalista, mediante la selección y la puesta en escena, organiza y visibiliza el material de la realidad social. Nos muestra lo que ha sociedad ha entendido, entiende o entenderá por realidad. Nos ofrece puntos de vista para explorar y entender el mundo que compartimos. (Sellés, 2008: 8)

En el documental lineal la elección y el control está en manos del documentalista, $\mathrm{y}$ al público se pide solo un tipo de participación cognitiva, a diferencia del documental interactivo donde el poder es entregado al usuario al que además de la interpretación mental se exige una participación física en cuanto a toma de decisiones que se traduce en la utilización del ratón y del teclado, el movimiento por el escenario virtual, la escritura, etc. (Gifreu, 2013; 2010). 


\section{MONOGRÁFICO}

Esta respuesta física que se demanda al público se lleva a cabo a partir de los elementos propios que plantea el documental interactivo: las modalidades de navegación y de interacción (Gifreu, 2013). Las modalidades de representación de Nichols, que definían lo que hasta ahora ha sido el documental clásico, se reformulan gracias a las características que ofrecen las tecnologías digitales de navegación, interacción y participación. En palabras de Arnau Gifreu

(...) las modalidades de representación de Bill Nichols eran pertinentes en el caso de los documentales lineales, pero en el caso que nos ocupa -el análisis de los documentales interactivos- los componentes clave son las modalidades de navegación y de interacción (2013: 115).

\subsubsection{Una aproximación al concepto de webdoc}

Esta nueva forma va a pasar a denominarse por diferentes autores como documentales web (o en su forma abreviada, webdoc), documentales multimedia interactivos, webdocs, documentales transmedia o iDocs, entre otros (Bruzzi, 2000; Gaudenzi, 2009; Gifreu, 2013; Goodnow, 2004; Renó, 2013; Scolari, 2013).

Del mismo modo, también encontramos diferentes puntos de vista a la hora de tratar de definir qué es un documental interactivo. A esto hay que sumar dos problemas de fondo: en primer lugar "la falta de aceptación o de no delimitar una corriente principal" (Gifreu, 2013: 136), y en segundo lugar el hecho de que diversos críticos cinematográficos y documentales ponen en duda que un documental interactivo pueda ser considerado como tal, lo que dificulta tratar de establecer una definición del mismo (Gifreu, 2013). Algunos autores han tratado de definir el término como una evolución del documental lineal, situada dentro del predominio de la convergencia digital. "Han asumido que el documental interactivo es básicamente vídeo y que su interactividad asociada es solo una manera de navegar a través de su contenido visual" (Gifreu, 2013: 137). No obstante, como matiza Gifreu (2013), estos autores intentaron definir esta nueva corriente cuando el concepto de interactividad se encontraba en un estadio anterior. Entre ellos se encuentran autores como Xavier Berenguer (2004), Carolyn Handler Miller (2004) y Katherine Goodnow (2004). 
El soporte multiplataforma como clave de éxito de la Narración Transmedia... 312

Definiciones más actuales son las aportadas por Gifreu (2013), Gaudenzi (2013) y Scolari (2013), aunque no son las únicas. Para Gifreu:

Se trata de una forma emergente, pendiente de exploración y de delimitación, y fruto de una doble hibridación: entre audiovisual -género documental- e interacción -medio digital interactivo-, y entre información -contenidos- y entretenimiento -interfaz navegable-. (2013:148).

Además añade que:

Los documentales interactivos pretenden documentar, representar e interactuar con la realidad, lo que conlleva la consideración y la utilización de un conjunto de técnicas o modos para hacerlo (modalidades de navegación e interacción), los cuales se convierten, en esta nueva forma de comunicación, en el elemento clave para alcanzar los objetivos del documental. (Gifreu, 2013: 148).

Para Gaudenzi los documentales interactivos son “(...) digital non-linear narratives that use new media to relate and describe reality" (2013: 10). Mientras que Scolari, por su parte, los define como "un nuevo tipo de relato de base hipertextual (o sea, no lineal) en el cual el contenido se fragmenta y el usuario debe navegar en una red de textos escritos, fotos, vídeos y grabaciones de audio" (2013: 197). Según este último, algunas de las mejores experiencias de narrativas transmedia pertenecen al género documental, que supone "un tipo de creación que a menudo busca integrar dentro de un contenedor audiovisual el interés social con la participación ciudadana" (Scolari, 2013: 197).

De estas definiciones se pueden extraer dos características fundamentales de los documentales interactivos: la ruptura de la linealidad de los documentales tradicionales, y la búsqueda de la participación de los espectadores-usuarios que pasan a adoptar un papel activo que hasta ahora no tenían. En palabras de Gifreu,

el documental interactivo, pues, difiere del documental tradicional, ya que permite una representación no lineal de la materia, en general a través de secciones de información, cercano en cierto modo al tratamiento periodístico, y 


\section{MONOGRÁFICO}

coloca en un papel activo al usuario para discernir la cantidad de contenido que quiere ver y en qué orden (2013: 118).

\subsubsection{Interactividad y multimodalidad en los webdocs}

Como se ha señalado, una de las principales características que presentan los documentales interactivos es el grado de interacción que introduce con respecto al receptor-usuario, que pasa a adoptar un papel activo en contraposición al papel pasivo que hasta el momento venía desempeñando. Este nuevo medio abandona el tradicional enfoque lineal en el que el espectador únicamente visiona la historia (Bruzzi, 2002) e introduce fórmulas narrativas que otorgan un mayor protagonismo al usuario en cuanto a participación-interacción posibilitando la interacción física con la historia gracias a una composición abierta que permite la navegación a través del material (Choi, 2009). Es decir, los documentales interactivos constituyen obras con carácter abierto que permiten al usuario interactuar con el contenido (Rodríguez \& Molpeceres, 2013). La narración no lineal permite enriquecer el contenido y dotar al espectador de una experiencia más variada, completa e inmersiva (Gifreu, 2011). Antes el lector se limitaba a visionar lo que se le presentaba en la pantalla, ahora las herramientas interactivas le permiten participar de la experiencia. "A diferencia de los documentales tradicionales, estos nuevos documentales permiten a los usuarios tener una experiencia única, ofreciéndoles opciones y control sobre el mismo" (Rodríguez \& Molpeceres, 2013: 254).

Los documentales interactivos van a ofrecer diferentes tipos de navegación, interacción y participación. El usuario podrá acceder a un contenido que presenta varios caminos de lectura, de tal manera que podrá establecer su propio discurso cambiando su orden e incluso llegando a modificarlo. Un hecho que está ligado al concepto de "experiencia documental" que aparece en los nuevos documentales (Rodríguez \& Sánchez, 2014).

\section{Material y métodos}

El objeto de estudio de la investigación que aquí se plantea se centra en el proyecto que lleva por título "Las Sinsombrero", una iniciativa fruto de la colaboración entre Radio Televisión Española (RTVE), Intropia Media y Yolaperdono, que 
El soporte multiplataforma como clave de éxito de la Narración Transmedia... 314

tiene como objetivo contribuir a la recuperación y el reconocimiento de las artistas femeninas de la denominada Generación del 27. En primer lugar ha de decirse que la investigación que aquí se presenta se fundamenta en la definición aportada por Scolari, quien define las NT como "un tipo de relato donde la historia se despliega a través de múltiples medios y plataformas de comunicación, y en la cual una parte de los consumidores asume un rol activo en ese proceso de expansión" (2013: 46). Dentro de esta definición se incidirá especialmente en la última parte de la misma, es decir, en el papel activo que juega el usuario pero entendido éste no solo como la posibilidad que tiene de interaccionar con el contenido, sino también como el rol que puede adoptar éste como generador de contenido, ampliando con ello el universo narrativo de la historia. Este último aspecto relacionado con el citado papel activo del usuario, se considera aquí como el elemento que verdaderamente sirve para diferenciar este tipo de narraciones de otras similares. Un ejemplo que ilustra esta aportación sería el proyecto de "Panzer Chocolate", el cual aunque puede ser considerado como transmedia, ya que, ha sido diseñado para expandir el relato base, en este caso la película del mismo nombre a través de una NT que queda plasmada en una novela, un cómic, un videojuego y una aplicación, los cuales se pueden consumir de forma autónoma y permiten la interacción del usuario con los mismos, éste solo adquiere un rol verdaderamente activo en el momento que entra en escena el elemento transmediático de la aplicación móvil "Panzer Movie". A través de esta app el usuario interactúa con los contenidos adicionales hasta el punto de poder contribuir a la historia con sus propias decisiones narrativas (Rodríguez y Molpeceres, 2015).

La elección de dicho objeto de estudio, por lo tanto, se fundamenta en el hecho de que se trata de un ejemplo actual, que comenzó en 2015 y que en estos momentos continúa creciendo, que está compuesto por una narración base, bajo el formato de un documental clásico que ha sido emitido por Televisión Española ${ }^{1}$, el cual a su vez ha expandido su universo narrativo en otros productos mediáticos y en diversos soportes multiplataforma. A todo ello se suma que el mencionado proyecto contempla la participación de los usuarios en narración mediante la utilización de las redes sociales y la propia página web del proyecto. 


\section{MONOGRÁFICO}

Teniendo en cuenta las características que presenta "Las Sinsombrero", se plantea desde el punto de vista metodológico su análisis como estudio de caso (Yin, 1994). Dicho análisis se ha articulado teniendo en cuenta la siguientes hipótesis de investigación:

1. La producción y distribución multiplataforma puede conllevar a dos tipos de narraciones en la medida en que permite la posibilidad de que la narración base se expanda en diferentes soportes y plataformas bajo un modelo crossmedia o transmedia. Como consecuencia de esto, la expansión del universo narrativo a través de un modelo transmediático pone de relieve la verdadera potencialidad del soporte digital multiplataforma, puesto que es en estos medios donde se encuentran las mayores innovaciones desde el punto de vista narrativo, ya que permiten contemplar la participación de los usuarios con respecto a la narración base, a diferencia del modelo crossmedia que no permite tal posibilidad.

Esta hipótesis, a su vez, se concreta en una serie de objetivos generales y específicos:

1. Objetivos generales:

a. Analizar la estructura narrativa que presenta el proyecto "Las Sinsombrero".

b. Determinar la función que cumplen cada una de las plataformas a través de las cuales se expande la historia.

2. Objetivos específicos:

a. Delimitar dentro de cada una de las plataformas a través de las que se expande el proyecto los elementos narrativos que pueden considerarse como multiplataforma, crossmedia y como transmedia.

b. Determinar las principales innovaciones que presentan dichos elementos identificados, desde el punto de vista narrativo.

Para abordar dichos objetivos de investigación se plantea la utilización de una perspectiva metodológica fundamentalmente cualitativa, a través de un análisis de contenido del proyecto "Las Sinsombrero". 
El soporte multiplataforma como clave de éxito de la Narración Transmedia... 316

MONOGRÁFICO

\section{Análisis y resultados}

A continuación se aporta el análisis de la estructura narrativa que caracteriza al proyecto "Las Sinsombrero".

\subsection{Elementos narrativos del proyecto "Las Sinsombrero"}

La estructura narrativa del proyecto "Las Sinsombrero" se extiende a través de diferentes plataformas. Así, a partir del documental para televisión (que representa la narración base) se creó un webdoc y, paralelamente, la historia se expandió también a través de las redes sociales. A ello que suma que, además, a lo largo del tiempo la narración ha dado lugar a un proyecto educativo, un libro, una exposición y un wikiproyecto. En los siguientes subepígrafes describimos cada una de las plataformas y su función en la expansión de la historia:

\subsubsection{Documental}

El proyecto comenzó con un documental clásico dirigido por Tània Balló, Manuel Jiménez Núñez y Serrana Torres en 2015. Esta pieza se estrenó el 9 de octubre del mismo año en la serie de documentales "Imprescindibles" de La 2 de Radio Televisión Española. Tras su emisión, el documental se incorporó a la sección de contenidos $A$ la carta de la web www.rtve.es, donde sigue disponible actualmente. A lo largo de sus 60 minutos de duración, la obra narra la historia de ocho mujeres de la Generación del 27 (Concha Méndez, Marga Gil-Roësset, Josefina de la Torre, Maruja Mallo, Ernestina de Champourcín, Rosa Chacel, María Teresa León y María Zambrano) a través del testimonio de diferentes especialistas en sus obras; así como de la voz de algunas de las protagonistas $\mathrm{y}$, en ocasiones, de algunos de sus familiares. A partir de este documental, cuya función en el conjunto del proyecto se considera la de narración base, la historia de "Las Sinsombrero" comenzó a expandirse por otras plataformas.

\subsubsection{Webdoc}

Tras la emisión en televisión de "Las Sinsombrero", la historia saltó a la web con la realización de este documental interactivo alojado en la página www.lassinsombrero.com

DOI: ri14.v14i2.967 | ISSN: 1697-8293 | Año 2016 Volumen 14 Nº 2 | ICONO14 


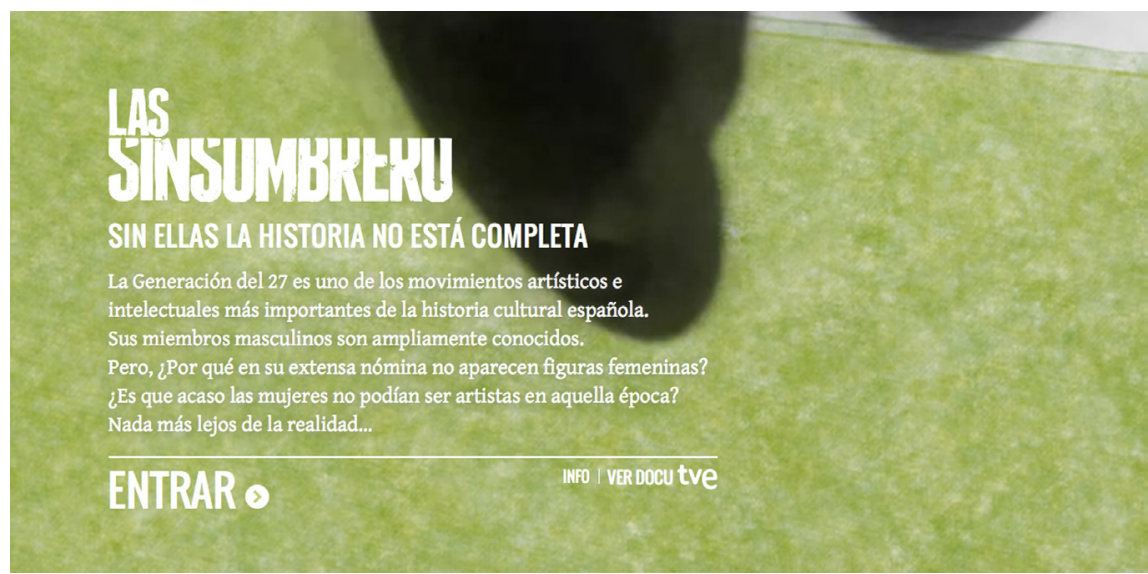

Figura 1: Página de inicio del webdoc "Las Sinsombrero". Fuente: www.rtve.es/lassinsombrero/es

El webdoc está estructurado en tres partes fundamentales: el documental, la sección Explora media y la sección Participa. En primer lugar, la sección en la que aparece la pieza audiovisual incorpora la novedad de mostrar el documental fragmentado con indicaciones del tiempo dedicado a cada una de las ocho artistas (Rosa Chacel, Ernestina de Champourcín, Marga Gil Roësset, Concha Méndez, Maruja Mallo, María Zambrano, Josefina de la Torre y María Teresa León), de manera que los usuarios pueden visualizar la(s) parte(s) que deseen y en el orden que estimen oportuno.

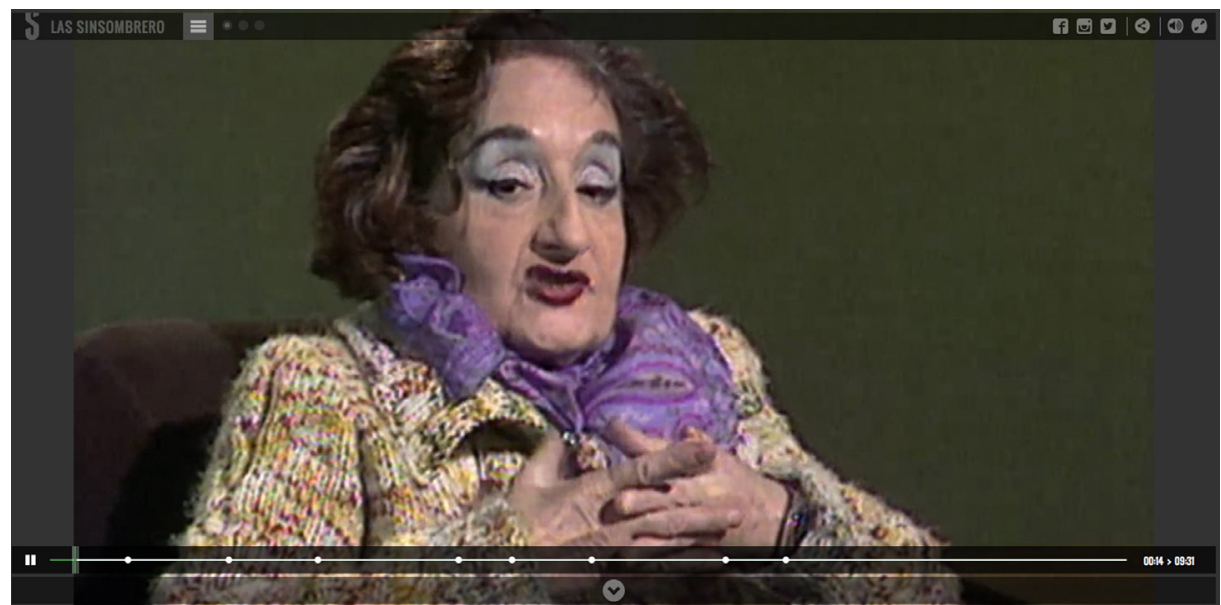

Figura 2: Captura del documental fragmentado. Fuente: www.rtve.es/lassinsombrero/es 
Por su parte, en la sección Explora Media, el webdoc ofrece la posibilidad de acceder a un conocimiento más exhaustivo sobre la vida y obra de las mujeres de la Generación del 27. Así, a través de una interfaz con fotografías de las ocho artistas, el usuario puede seleccionar cualquiera de ellas y acceder a una subpágina con diferentes contenidos multimedia. Como consecuencia, existe un microsite para cada una de las mujeres, donde además de una breve pieza audiovisual (formada por fragmentos del propio documental, con una duración que varía entre el minuto y medio y los tres minutos y medio) también se pueden visualizar algunas de sus obras, fotografías personales, apuntes o cartas, entre otros documentos, todos ellos acompañados de un breve texto explicativo. Cada uno de estos microsites contribuyen a aportar una manera alternativa de explorar la historia, de modo que los usuarios pueden hacerlo de manera interactiva y según sus preferencias.

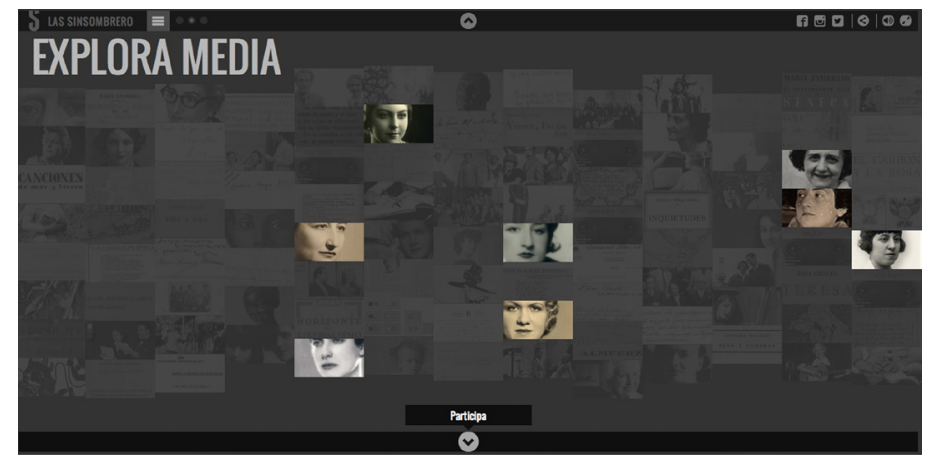

Figura 3: Espacio de selección (interfaz). Fuente: www.rtve.es/lassinsombrero/es

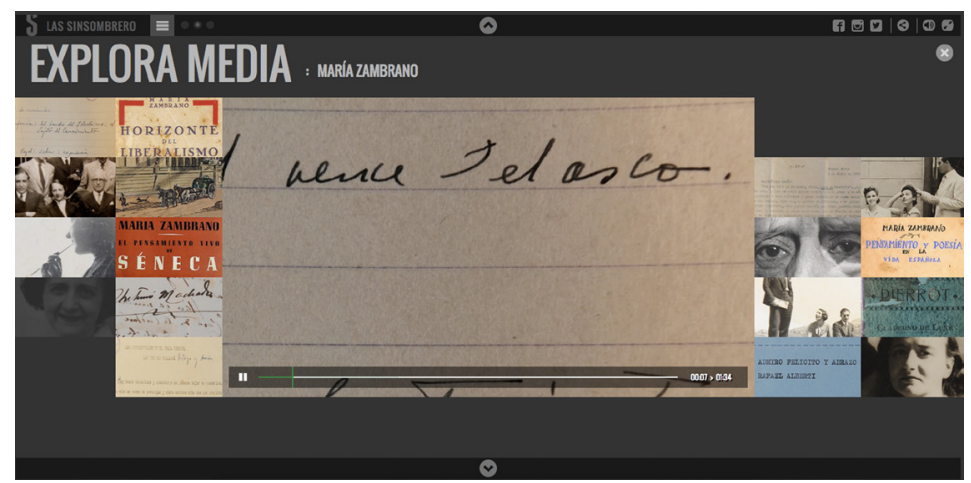

Figura 4: Microsite dedicado a María Zambrano. Fuente: www.rtve.es/lassinsombrero/es 


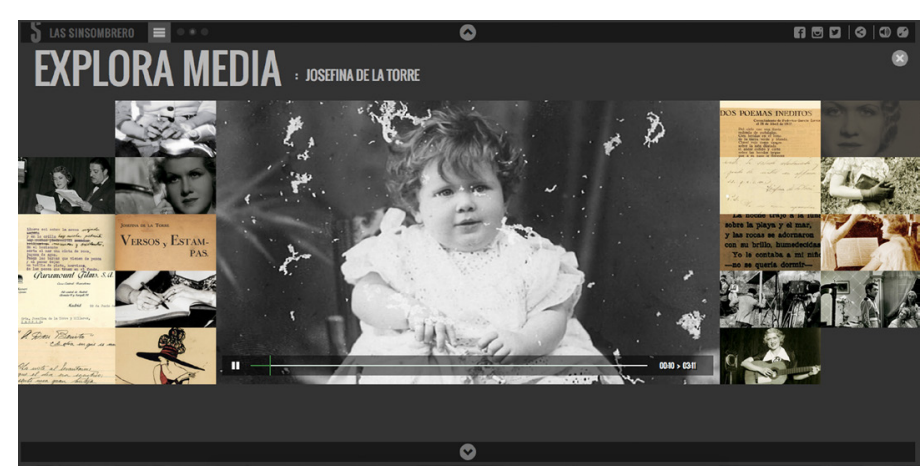

Figura 5: Microsite dedicado a Josefina de la Torre. Fuente: www.rtve.es/lassinsombrero/es

Por último, el webdoc contiene la sección denominada Participa, en la que invita a los usuarios a que contribuyan a contar la historia de "Las Sinsombrero" recuperando el testimonio de otras mujeres que consideren que es necesario recordar, ya sea por la importancia de su obra o de su profesión. Para ello, sólo tienen que subir una fotografía a Twitter o Instagram e incorporar en la publicación el hashtag \#misinsombrero, de manera que todas las imágenes aportadas por los usuarios aparecen recogidas en ambas redes sociales y bajo una misma etiqueta, lo que facilita su búsqueda y recopilación. Además, todas las fotografías aportadas por los usuarios aparecen también recogidas en la sección Participa del webdoc, contribuyendo de este modo a expandir el universo de "Las Sinsombrero" y a incrementar la narración. En última instancia, esta participación activa de los usuarios hace que el proyecto pueda ser considerado una narrativa transmedia pues la implicación de los usuarios es un eje fundamental para la historia.

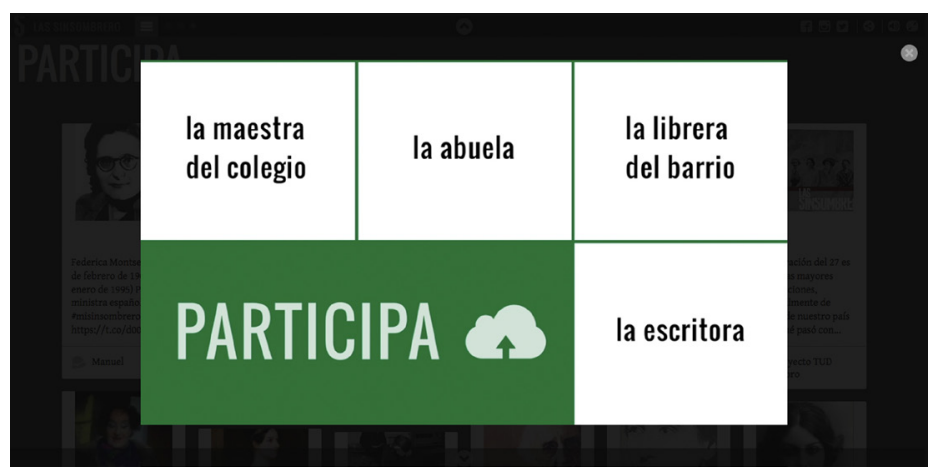

Figura 6: Sección Participa. Fuente: www.rtve.es/lassinsombrero/es 


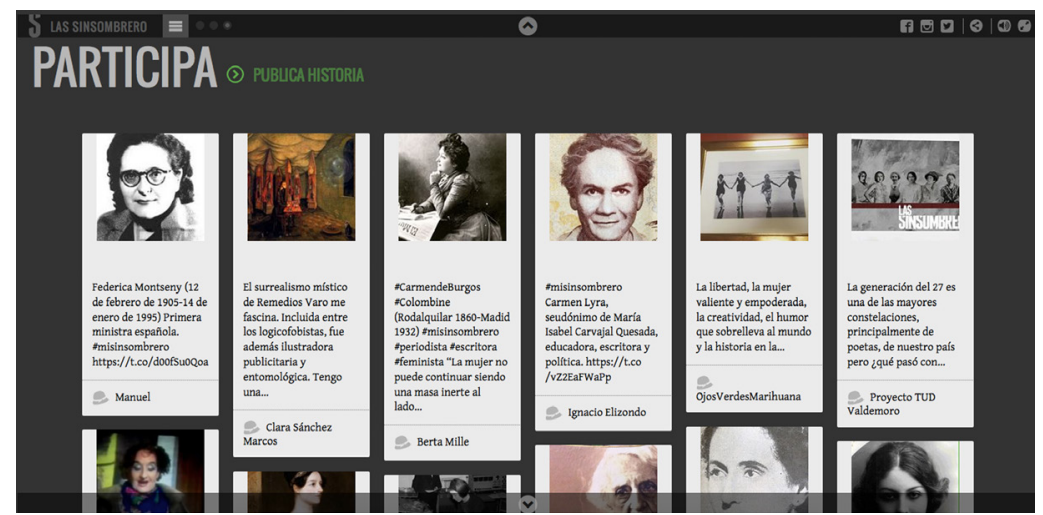

Figura 7: Contenidos publicados por los usuarios. Fuente: www.rtve.es/lassinsombrero/es

\subsubsection{Redes sociales}

En paralelo al resto de soportes, el proyecto de "Las Sinsombrero" ha empleado la visibilidad facilitada por redes sociales como Facebook (www.facebook.com/ lassinsombrero),Twitter (@lassinsombrero) o Instagram (@lassinsombrero). Estos espacios no sólo se han utilizado para difundir las noticias y eventos relacionados con el proyecto, sino también para apoyar la narración base con datos, imágenes y la participación de los usuarios. Como se ha indicado previamente, Twitter e Instagram, han sido también las plataformas empleadas para acoger las fotografias \#misinsombrero de los usuarios. En definitiva, además de actuar como herramientas de comunicación, las redes sociales también han aportado datos al proyecto (en forma de textos, imágenes, comentarios, etc.) y han acogido el feedback de los usuarios.

\subsubsection{Proyecto educativo}

En colaboración con leer.es (el portal del Ministerio de Educación, Cultura y Deporte destinado a fomentar la lectura), el proyecto extiende su presencia al ámbito educativo con la elaboración de materiales didácticos destinados a estudiar la vida de estas artistas de la Generación del 27 y profundizar en su legado. Así, por ejemplo, "Las Sinsombrero" y leer.es han creado dos juegos para que el alumnado descubra de manera interactiva diferentes aspectos de la obra de las ocho mujeres. Este proyecto representa la extensión de la narración al ámbito educativo, siendo su objetivo que la historia de "Las Sinsombrero" llegue al alumnado y se incorpore a su formación. 


\section{MONOGRÁFICO}

\subsubsection{Libro}

El pasado 23 de febrero de 2016 tuvo lugar la publicación del libro "Las Sinsombrero. Sin ellas la historia no está completa" (de la editorial Espasa), escrito por Tania Balló. A lo largo de sus páginas, la autora recupera las historias de las mujeres de la Generación del 27, con novedades como la incorporación de la historia de la pintora Ángeles Santos. Este soporte es un nuevo ejemplo de cómo la narración se adapta un nuevo formato, en esta ocasión el formato papel, para continuar expandiéndose y ampliar su alcance.

\subsubsection{Exposición}

Para destacar el legado de estas artistas, el proyecto planea organizar a lo largo de 2017 una exposición itinerante. De esta manera, la historia de "Las Sinsombrero" pretende ser llevada a los museos con el objetivo de destacar la influencia de estas mujeres en la sociedad de la época y acercar así su obra a los visitantes.

\subsubsection{Wikiproyecto}

El wikiproyecto "Las Sinsombrero" se está desarrollando actualmente en colaboración con Wikipedia España con el objetivo de difundir la obra de las mujeres pertenecientes a la Generación del 27 a través de la creación, mejora y ampliación de artículos o de la recopilación de bibliografía relacionada con ellas. En última instancia, con este wikiproyecto se persigue lograr que la información disponible en la Wikipedia en relación a "Las Sinsombrero" sea de calidad y que la plataforma sirva para apoyar la realización de actividades docentes.

\subsection{Principales innovaciones que presenta la estructura narrativa del proyecto "Las Sinsombrero"}

Los elementos narrativos identificados en el proyecto "Las Sinsombrero" conducen a una segunda parte de análisis, en este caso centrado en la variable de interacción-participación del usuario, en relación a la estructura narrativa.

A este respecto se puede establecer que los siete elementos identificados responden a dos modelos narrativos, uno crossmedia y otro transmedia, y es precisamente la posibilidad de interacción-participación de los usuarios la que permite 
hacer tal distinción. Es decir, por una parte los elementos del proyecto objeto de estudio elaborados bajo un soporte analógico: el documental televisivo, el proyecto educativo, la exposición y el libro tienen como resultado una expansión del universo narrativo a través de un sistema multiplataforma que desencadena en un modelo de narración crossmedia, puesto que estos finalmente pueden ser consumidos de forma autónoma. Su principal característica radica en que la interacción-participación de los usuarios en los citados elementos se podría considerar como pasiva, en tanto en cuanto, sólo son meros consumidores de contenidos, al igual que ocurría en este caso en el citado ejemplo en líneas anteriores "Panzer chocolate" (2013), con la novela, el videojuego y el cómic. Por otra parte, los elementos que han sido distribuidos bajo un soporte multiplataforma digital: webdoc, wikiproyecto y las redes sociales presentan como principal característica la posibilidad que ofrecen a los usuarios de expandir el universo narrativo desde un punto de vista activo, de tal modo que estos pueden llevar a cabo una contribución al contenido base. Esta particularidad es la que permite hablar de un verdadero modelo narrativo transmediático, al igual que ocurría en el caso del proyecto "Panzer chocolate" (2013) con el elemento transmedia de la app "Panzer Movie".

Aunque es su conjunto los siete elementos conforman un proyecto multiplataforma, se podría establecer a su vez como narración base dentro del modelo de narrativa crossmedia el documental televisivo y dentro de la narración transmedia el webdoc. Este aspecto pone de manifiesto la importancia de las características del soporte multiplataforma a través del cual se despliega el resto del universo narrativo, ya que es el digital el que mayores potencialidades ofrece, no solo a los creadores-realizadores del documental sino también, y especialmente, de cara a la contribución que los usuarios pueden hacer a dicha historia base. A este respecto cabe señalar que el engranaje fundamental para que se produzca dicha aportación son las redes sociales, las cuales actúan como un vehículo perfecto para la expansión del universo narrativo de la historia.

Relacionado intrínsecamente con estos aspectos se encuentra la función que cumple el sistema multiplataforma. Concretamente dentro del proyecto “Las Sinsombrero", ésta puede adoptar dos dimensiones como se puede apreciar en la tabla que se muestra a continuación: 


\section{MONOGRÁFICO}

\begin{tabular}{|c|c|c|c|}
\hline Elemento narrativo & Modelo narrativo & $\begin{array}{c}\text { Tipo de contribu- } \\
\text { ción a la narra- } \\
\text { ción }\end{array}$ & $\begin{array}{l}\text { Función del so- } \\
\text { porte multiplata- } \\
\text { forma }\end{array}$ \\
\hline Documental Televisivo & Crossmedia & Pasiva & $\begin{array}{c}\text { Interacción-participa- } \\
\text { ción-navegación por el } \\
\text { universo narrativo }\end{array}$ \\
\hline Proyecto educativo & Crossmedia & Pasiva & $\begin{array}{c}\text { Interacción-partici- } \\
\text { pación-navegación a } \\
\text { través del universo } \\
\text { narrativo }\end{array}$ \\
\hline Libro & Crossmedia & Pasiva & $\begin{array}{l}\text { Interacción-participa- } \\
\text { ción-navegación por el } \\
\text { del universo narrativo }\end{array}$ \\
\hline Exposición & Crossmedia & Pasiva & $\begin{array}{l}\text { Interacción-participa- } \\
\text { ción-navegación por el } \\
\text { del universo narrativo }\end{array}$ \\
\hline Webdoc & Transmedia & Activa & $\begin{array}{l}\text { Interacción-partici- } \\
\text { pación-generación de } \\
\text { contenidos nuevos al } \\
\text { universo narrativo }\end{array}$ \\
\hline Wikiproyecto & Transmedia & Activa & $\begin{array}{l}\text { Interacción-partici- } \\
\text { pación-generación de } \\
\text { contenidos nuevos al } \\
\text { universo narrativo }\end{array}$ \\
\hline Social Media & Transmedia & Activa & $\begin{array}{l}\text { Interacción-partici- } \\
\text { pación-generación de } \\
\text { contenidos nuevos al } \\
\text { universo narrativo }\end{array}$ \\
\hline
\end{tabular}

Tabla 1: Fuente: Elaboración propia

La primera de ellas correspondería con un modelo: Interacción- participaciónnavegación, desde el punto de vista de simple consumo de los usuarios por los contenidos; y la segunda con un modelo: Interacción-participación-creación desde el punto de vista de contribución de los usuarios de contenidos nuevos.

\section{Discusión y conclusiones}

El análisis realizado permite constatar la hipótesis de partida, es decir, el proyecto documental "Las Sinsombrero" viene caracterizado por dos modelos de narración: uno crossmedia, el cual genera una participación de los usuarios como 
meros consumidores de contenidos, por lo tanto no hay contenidos nuevos a los proporcionados por la producción y distribución del proyecto. Y un modelo transmedia el cual, a diferencia del anterior, sí genera participación de los usuarios, como generadores de contenidos nuevos que contribuyen verdaderamente a expandir el universo narrativo de la historia. Como consecuencia de esto se puede establecer que una de las principales innovaciones a las que ha contribuido el modelo de narración multiplataforma, es sin duda a la creación de nuevas narrativas como la transmedia, cuyo foco fundamental se centra ahora en la experiencia de los usuarios a la hora de ponerse en contacto con la realidad contada, y para ello es imprescindible generar canales de participación. En este sentido destacan dentro del documental objeto de estudio la utilidad que se les da a las redes sociales como elemento básico para tal fin. Es decir, gracias a plataformas como Facebook, Instagram, y Twitter, los usuarios han podido contribuir de forma original e inédita con sus aportaciones a la narración base, puesto que éstas son fruto de su propia experiencia. Dentro del formato periodístico documental, esta nueva concepción narrativa supone importantes avances no sólo a la hora de producir el material informativo, sino también a la hora de consumirlo. La estructura fragmentada que caracteriza ahora al formato webdoc, y que queda materializada dentro del objeto de estudio, en la identificación que se ha aportado fruto del análisis de los distintos elementos narrativos, ya sean considerados como crossmedia o transmedia, junto con la posibilidad que da el soporte digital (redes sociales) para que los usuarios puedan interaccionar y participar reinventa las formas de acercarnos a la realidad; una realidad que los usuarios cada vez quieren tener más cerca y sentirse protagonistas. Muestra de ello son las múltiples aportaciones que los usuarios han ido realizando dentro del formato webdoc de "Las Sinsombrero" fundamentalmente en el apartado de Participa, a través de sus contribuciones en las redes sociales y en el wikiproyecto (ambos en el soporte digital).

\section{Notas}

[1] Disponible en: www.rtve.es/alacarta/videos/imprescindibles/imprescindibles-sin-sombrero/3318136/ 


\section{Referencias}

Area, M \& Pessoa, T. (2012). De lo sólido a lo líquido: Las alfabetizaciones ante los cambios culturales de la Web 2.0. Comunicar, 38. doi: 10.3916/C38-2011-02-01 Berenguer, X. (2004), Una dècada deinteractius. Temes de Disseny, 21, 30-35.

Britain, C. (2009). Raising Reality to the Mythic on the Web: The Future of Interactive Documentary Film. North Carolina: Elon University.

Bruzzi, S. (2000). New Documentary: a critical introduction. New York: Routledge. Caldevilla, D. (2009). Democracia 2.0: La política se introduce en las redes sociales. Revista Pensar la Publicidad, 3(2). Recuperado de http://goo.gl/K4zujp el 7 de abril de 2016.

Costa, C. \& Piñeiro, T. (2012). Nuevas narrativas audiovisuales: multiplataforma, crossmedia y transmedia. El caso de Águila Roja (RTVE). Icono14, 10(2). doi: 10.7195/ri14.v10i2.156

Díaz-Campo, J. (2014). Interactividad y participación en las páginas web de los principales diarios españoles. Revista de Comunicación Vivat Academia, 127. Recuperado de http://goo.gl/LJPRq5 el 7 de abril de 2016.

Gaudenzi, S. (2009). Digital interactive documentary: from representing reality to co-creating reality [trabajo de investigación]. Londres: University of London, Centre for Cultural Studies (CCS) of Goldsmiths.

Gifreu, A. (2010). El documental interactivo. Una propuesta de modelo de análisis (Pre-tesis, Universitat Pompeu Fabra). Recuperado de http://goo.gl/ViDWPQ el 8 de abril de 2016.

Gifreu, A. (2013). El documental interactivo. Evolución, caracterización y perspectivas de desarrollo. Barcelona: Editorial UOC.

Goodnow, K., Cordova, V. \& Venegas, H. (2004). ICT and Multicultural Practice. Bergen: InterMedia.

Handler, C. (2004). Digital Storytelling: A Creator's Guide to Interactive Entertainment. Oxford: Focal Press.

Jenkins, H. (2003). Transmedia Storytelling: Moving characters from books to films to video games can make them stronger and more compelling. Technology Review. Recuperado de http://goo.gl/6nkcU2 el 7 de abril de 2016.

Jenkins, H. (2007). Transmedia Storytelling 101. Confessions of an AcaFan. Recuperado de http://goo.gl/JZmFZ7 el 7 de abril de 2016. 
El soporte multiplataforma como clave de éxito de la Narración Transmedia... 326

Jenkins, H. (2008). Convergence culture. La cultura de la convergencia de los medios de comunicación. Barcelona: Paidós.

Jenkins, H. (2009). The Revenge of the Origami Unicorn: Seven Principles of Transmedia Storytelling. Confessions of an Aca-Fan (blog), 12 de diciembre. Recuperado de http://goo.gl/HsQSch el 7 de abril de 2016.

Jenkins, H. (2010). Transmedia Storytelling and Entertainment: An annotated syllabus. Continuum, 24(6), 943-958. doi: 10.1080/10304312.2010.510599

Jenkins, H. (2014). Transmedia 202: Reflexiones adicionales. Confessions of an Aca-Fan (blog), 8 de septiembre. Recuperado de http://goo.gl/08ig1w el 7 de abril de 2016.

López, X. (2011). Rasgos de la estrategia de los cibermedios gallegos en su empeño por promover la experimentación para el cambio de modelo periodístico. Estudios sobre el mensaje periodístico, 17(1). doi: 10.5209/rev_ESMP.201.v17.n1

Luizzi, A. (2014). Transmedia Historytelling. De Documentales Interactivos y Géneros Híbridos. En F. Higaray \& A. Lovato (Eds.) Hacia una Comunicación Transmedia (pp. 65-86). Rosario: UNR Editora. Recuperado de http://goo.gl/ lpnm2L el 8 de abril de 2016.

Orihuela, J.L. (2002). Los nuevos paradigmas de la comunicación. eCuaderno (blog). Recuperado de http://goo.gl/OCLzl9 el 7 de abril de 2016.

McLuhan, M. (1964). Understanding Media: The Extensions of Man. Nueva York. New American Library.

Meso, K. (2006). Introducción al ciberperiodismo. Breve acercamiento al estudio del Periodismo en Internet. Bilbao: Servicio editorial de la Universidad del País Vasco, Euskal Herrico Unibertsitateko Argitalpen Zerbitzua

Molpeceres, S. \& Rodríguez, M.I. (2014). La inserción del discurso del receptor en la narrativa transmedia: el ejemplo de las series de televisión de ficción. CIC Cuadernos de Información y Comunicación, 19. Recuperado de http://goo.gl/ pECeqQ el 8 de abril de 2016.

Moreno, I. (2001). Genoma digital. Anàlisi, 27, 101-114. Recuperado de http:// goo.gl/utVdLk el 7 de abril de 2016.

Nichols, B. (1997). La representación de la realidad: cuestiones y conceptos sobre el documental. Barcelona: Paidós. 
Paíno, A. \& Rodríguez, M.I. (2015). La expansión del universo narrativo en las series de ficción. La importancia de la audiencia activa como elemento clave y diferenciador en las narrativas transmedia. En C. Mateo y J. Herrero (Coords.) La pantalla insomne. Cuadernos Artesanos de Comunicación 90 (pp. 10401065). doi: $10.4185 / \operatorname{cac} 90$

Paíno, A. \& Rodríguez, M.I. (2016). Renovarse o morir. Los 'docugames', una nueva estrategia transmedia que reinventa las formas de transmitir la realidad. Icono 14, 14. doi: 10.7195/ri14.v14i1.908

Postman, N. (1992). Technopoly: The surrender of culture to technology. New York: Knopf.

Renó, D. (2013). Diversidade de modelos narrativos para documentários transmídia. Doc on-Line: Revista digital de cinema documentario, 14. Recuperado de http://goo.gl/OteQEL el 8 de abril de 2016.

Rodríguez, M.I. \& Molpeceres, S. (2013). Los nuevos documentales multimedia interactivos: construcción discursiva de la realidad orientada al receptor activo. Historia y Comunicación Social, 18. doi: 10.5209/rev_HICS.2013.v18.44325

Rodríguez, M.I. \& Molpeceres, S. (2014). The Inside Experience y la construcción de la narrativa transmedia. Un análisis comunicativo y teórico-literario. C.I.C Cuadernos de Información y Comunicación, 19, 315-330. doi: 10.5209/rev_ CIYC.2014.v19.43918

Rodríguez, M.I. \& Molpeceres, S. (2015). Hacia un nuevo modelo de construir, transmitir y compartir narrativas. Estudio de caso de Panzer Chocolate. En Rodríguez, R. \& Tur-Viñes, V. (Coord.) Narraciones sin fronteras. Transmedia storytelling en la ficción, la información, el documental y el activismo social y político. CAC $81^{\circ}$, (pp. 81-98). doi: 10.4185/cac81.

Rodríguez, M.I. \& Paíno, A. (2015). La creación del universo transmedia en la serie de ficción de RTVE "El Ministerio del Tiempo". Del guion literario al fenómeno fan de los "ministéricos". De los medios a los metamedios. Actas I Simposio Red Internacional de Investigación de Gestión de la Comunicación. Recuperado de https://goo.gl/xAFxoL el 8 de abril de 2016.

Rodríguez, M.I. \& Sánchez, A. (2014). La interactividad, hipertextualidad y multimedialidad al servicio del género documental. Estudio de caso del webdoc En el reino del plomo de Rtve.es. En B. León (Coord.) Nuevas miradas al documental (pp. 82-94). Salamanca: Comunicación Social. 
Sellés, M. (2008). El documental. Barcelona: Editorial UOC.

Scolari, C. (2010): Ecología de los medios. Mapa de un nicho teórico. Quaderns del CAC 34, vol. XIII (1). Recuperado de http://goo.gl/ff03p6 el 8 de abril de 2015. Scolari, C.A., Jiménez, M. y Guerrero, M. (2012). Narrativas transmediáticas en España: cuatro ficciones en busca de un destino cross-media. Comunicación y Sociedad, 25 (1),137-163.

Scolari, C.A. (2013). Narrativas transmedia: Cuando todos los medios cuentan. Barcelona: Deusto, S.L.U

Toffler, A. (1980). The Third wave, Canadá: Bantan books.

Yin, R. (1994). Case Study Research: Design and Methods. Thousand Oaks, CA: Sage Publications. 